\title{
Educational Hypermedia Resources Facilitator
}

\author{
Francisco José García ${ }^{1}$ \& Joaquín García ${ }^{2}$ \\ ${ }^{1}$ Computer Science Department - Science Faculty \\ Plaza de la Merced S/N - Salamanca (Spain) \\ University of Salamanca \\ ${ }^{2}$ Theory and History of Education Department - Education Faculty \\ Campus Canalejas. $\mathrm{P}^{\mathrm{o}}$ de Canalejas, 169 - Salamanca (Spain) \\ University of Salamanca \\ \{fgarcia, carrasco\}@usal.es
}

\begin{abstract}
Within the university the introduction of computers is creating a new criterion of differentiation between those who as a matter of course become integrated in the technocratic trend deriving from the daily use of these machines and those who become isolated by not using them. This difference increases when computer science and communications merge to introduce virtual educational areas, where the conjunction of teacher and pupil in the space-time dimension is no longer an essential requirement, and where the written text is replaced (or rather complemented) by the digital text.

In this article a historical defence is made of the presence of this new standard in the creation of digital educational resources such as the hyperdocument, as well as the barriers and technological problems deriving from its use. Furthermore, HyCo, an authoring tool, is introduced which facilitates the composition of hypertexts, which are stored as semantic learning objects, looking for that through of a simple and extremely intuitive interface and interaction model, any teacher with a minimum knowledge of computer science has the possibility of transforming his or her experience and knowledge into useful and quality hypermedia educational resources.
\end{abstract}

\section{Keywords}

Authoring tool; Hypermedia educational resources development; Human-Computer Interaction; Open hypermedia system; Semantic learning object.

\section{Introduction}

The act of leaving written evidence of their existence based on their experiences and discoveries is a differentiating trait of human beings. Until well into the $20^{\text {th }}$ century, the ability to read and write was a criterion of social differentiation, which has come to be a 
criterion of differentiation in the progress of nations at the end of that century and the beginnings of the $21^{\text {st }}$ century.

Within the university, and obviously on a different scale of magnitude, the introduction of computers is re-creating a new criterion of differentiation between those who become integrated as a matter of course in the technocratic trend deriving from the daily use of these machines and those who become isolated by not using them.

This difference increases when computer science and communications merge to introduce virtual education areas, where the conjunction of teacher and pupil in the space-time dimension is no longer an essential requirement, and where the written text becomes replaced (or rather complemented) by the digital text.

At this very moment, when the digital universe coexists with the written text and is threatening to replace it to a great extent, all those teachers allergic to the hardware/software binomial have been relegated to professional ostracism.

The objective of this article is to rescue those educators of quality, who have much to offer in an educational system, whether virtual or presential, as authors of teaching resources. For this purpose, author tools are made to measure for them: simple, friendly tools that encapsulate all the technical processes of the publication of contents anywhere (whether it be the virtual educational area, a rigid medium or the traditional printed text).

This article presents one of these author tools, so called the facilitator of the composition of hypertexts, or simply HyCo (García et al., 2003). However, we do not merely introduce a new software tool; the article also defends the evolution of the written text from orality to the modern hypertext as a way of, in turn, understanding the evolution of the educational process and the cultural legacy which is handed down from generation to generation.

\section{Processes of communication: From oral tradition to the hypertext}

An elementary criterion of epistemology is the one by which we differentiate between "reality" and "text". This criterion is established within an ontological reference 
framework which distinguishes between subject and object of knowledge. These simple terms condense the whole historical trajectory of the theory of knowledge. For the effects of this article, let it suffice to indicate the importance of analysing the details of the "text" that the subject constructs with the personal conviction and the collective consensus (value of truth) that what the text states refers (intentionality) to what the subject perceives, to what the subject proposes or to what the subject does. In contemporary culture the concept of education is associated with the assimilation of "texts" and the concept of educator with the work of building "lesson" strategies. It would be impossible to understand the actions of education outside a planning of textual contents, of going through (curriculum) texts. Even the fact of being a researcher is associated with the production of texts as the condition of being a social actor is with the handling of texts. Losing touch with the text appears sociologically as the beginning of a process of marginalization.

Among the complex elements that compose the "text" there is one of major importance if the content is to be established as a meaning that can be communicated: the system of speech or orality. The world of meanings is so wonderful and the values associated with it are so decisive that we sometimes forget the marvellous instrument with which we exchange thought contents. It is as if, engrossed in the cultural wonders of what we eat, we forget something basic, although not edible: the container. The value of the example is partial because the association between speech (orality) and the content of communication is more intimate than that existing between container and content. One way of being astonished at the communication qualities of orality is to compare this system of communication with other systems of animal communication. The existence of the instrument (orality) implies a whole range of evolutionary adaptations that characterise the species that has it. Birds that talk, trees that give warning, animals that give advice... are nothing but fictional characters in stories, products of the narrative abilities of human beings.

\subsection{Symbolic traits of the oral "text"}

A first approach to the uses of the term "text" can be made when we use the notion to refer to any mental construction that can be uttered, everything we can say that we are doing mentally. That is, the set of "speech acts" (Austin, 1962). Speech analysis has preferentially been made through the declaratory speech forms, statements that refer to 
facts that are susceptible to truth-falsehood. The process of incorporation to culture is thus fundamentally understood as a process of teaching, a chain of declaratory statements through which a subject learns the events of the world. This concentrates the whole problem of communication and the whole problem of culture in a problem of dealing with facts of the world and experiences of the world; and language as an accumulator of facts and experiences: a text on the world of things, of living beings and of human beings.

However, in the situation of oral communication we human beings do (Belinchón et al., 1994) much more than speak (Austin, 1962). This indicates that at the same time as the utterance many illocutionary acts take place, and many uses of language (besides that of declaring or stating facts). The basic element of communication is the production of the communicative instance: what one intends to do when one speaks, i.e. the illocutionary act that gives sense (not meaning). By means of the illocutionary act, the subject takes part in an intersubjective process, governed by rules, which is not merely reduced to communicating meanings; it becomes a way of life: we live by “languaging”.

Illocutionary acts refer to what one wants and what is shown in speech and other movements and signs. Because we have centred on meaning, and not on acts of communication, we have not heeded the body as an instrument of communication; even today this is still known as "non-verbal communication". What is wanted and what is said have a very contingent relationship to each other. This imperfect relationship is that which shows that language is a mechanism or instrument of communication. It occupies a privileged place within the overall system of intersubjective communication, but it also has limits. The nuances that a gesture brings to communication cannot be expressed orally. We are not inclined to a detailed analysis of these different mediating instruments of communication because we speak, gesticulate, ritualise, sing and dance involving the body. And the effectiveness of orality is so astonishing and enormous that all these other mediations remain hidden in the shadows.

This is a first chapter of text analysis: the communication act mediated in contexts of orality (Searle, 1969). A situation of interaction is thus never simply a teaching situation, but rather a communicative situation, because it is not a question merely of a "sender" of information (Corredor, 1999), but of persons involved in a web of 
intersubjective relations. The speech context is formed by several categories of elements, some linguistic and others extra-linguistic (Luque \& Alcoba, 1999); all together they contribute informational coherence and evidence of the communicative intention. All of this is in relation to the speech medium, the sender-receiver corporeal nature of sounds.

In the formal process of education, training in the use of language should not be reduced to using language as a grammatical tool or lexical system, but rather it should develop linguistic completion in all these skills, which decisively affect social communication.

\subsection{The oral text as an educational resource in cultures of primary orality}

We are accustomed to considering cultural evolution from the point of view of its objective productions, yet this is nothing but an ideological bias. We forget that, besides technological pressure, communicative pressure must also have played a large role, the slow progress in forms of communication with a two-fold objective: to improve the accuracy of the actions of communications and to improve the quality of preservation of the experience acquired in the group by means of communicational resources.

Gesture routines were a magnificent preserver of experience. This reservoir of memory of mental activity was later joined by another preserver of experience and action: language. We may never be able to decipher the mutual interdependencies between modes of speaking and modes of mental activity, dependencies between the modes of mental operations and the nature of the instruments, between the structure of action and the pattern afforded by the instrument.

Primary orality (we shall call secondary orality the system of oral communication used in literate cultural contexts) contains in the word and in the associated corporality the totality of representation and symbolic value. Attention and true value are given to hearing, memorization is the intellectual function par excellence; the processes of socialization are metaphorised in an "initiation", the initiate is the one who has heard the voice. Thus, the concept of orality contains three directions of meaning: communication in societies without writing, oral communication as a system of communication in itself, and a style of consciousness, which is supposed to create orality and is expressed with it. Many feel that scientific curiosity about orality, as a 
form of thought, began with the work of Milman Parry (doctoral thesis, 1928) on "The Traditional Epithet in Homer” (Parry, 1971; Havelock, 1991).

Speech developed at the same time as the conventions on meaning progressed; it is therefore a promoter of communication and thought. For millennia humans managed the affairs that made social functioning possible by using exclusively oral language, and this is still being done today, because this is the primary communicational form; primary, because it is fundamental, and primary because our biology genetically predisposes us to it.

Things are "world” because there are human beings who are trying to live in it by understanding it, searching for their place in it and creating a personal world. By the words that they exchange with each other human beings trace paths in the world along which reality can travel. In this way the experience of an event, consciousness, is associated with the communicative capacity of the experience through language.

This narrative capability is an aptitude of the mind to "reconstruct" the $I$, the we and everything else; it forms it for itself and for others. To a large extent the educational aim to encourage contents and promote attitudes with respect to the world, oneself and others coincides with the development of this "narrative sensibility" (Bruner, 1996). An entire fundamental chapter could be written on the formation of human beings as the promotion of narrative and conversational competence (Frisch, 1967), exercise in the use of the instruments and artifices of communication, "tools" that Vygotsky (1978) called for as mediators of the higher mental functions.

Pierre Lévy (1988) lists the traits of the mnemonic-reproducing process in societies of primary orality:

- The representations will be strongly interconnected, composing scenes with a strong internal coherence. A good example of this can be found in the oldest written texts of oral traditions: the Book of Genesis, The Iliad, the Gospels...

- The most relevant connections are of linear cause and effect, the relations between the elements of the scene are simple, direct, causal... Good examples of this are conversational tales.

- It contains references to concrete domains of thought, in which the fundamental 
outlines are familiar. Examples would be the parables of the Gospels.

- Representation is built upon vital problems, personal implications and a strong emotional charge. It is the theme of life with its priorities and existential questions which innervates the stories.

This set of characteristics describes a style of thought that is strongly contextualized (Denny, 1998). The sense of oral production may be cooperative, incorporating several subjectivities into the narration; in practice, "what there is to tell" is reached by successive approximations among interlocutors. Based on these approximations, the like-dislike of the conversation is calibrated (conversational skills). The process of interpretation in orality implies on the part of the listener a reconstruction of the meaning, which will also incorporate his or her own expectations (that is why a conversation before a person who is disliked is defensive, or incites mistrust and derivations that confirm doubts...).

Societies of primary orality do not have schools for teaching these functions, but this does not mean that they are less educational, since they have the systems that best accommodate their state as regards education. Neither are they less rational; rather, they use in their world the forms that are possible in that context and that best accommodate their mental activity. Myth is a magnificent invention within that context, as is ritual and dramatization... as well as the first exercises in the graphic function (Neolithic paintings).

For all of these reasons it can be affirmed with H. Maturana (1991) that cultures are networks of conversations, conversational organizations. It must have been progress made in the transaction of meaning that led humans to search for and perfect new mediators and instruments of communication. Culture evolved with them, it generated “cultures" of primary orality (oral societies with no technique for the graphic transcription of symbols). In these cultures one could identify an author by the public function of "having or not having the word", of being a source of counsel or the preserver of collective experiences and memory.

\subsection{The written text and the development of mental activity}

Writing is usually described as mere transcription of speech (Saussure, 1952) and as 
dependent on the word, especially in cases of syllabic and consonantal writing. But in the context developed in this paper it has other aspects that function as a complex warp that is comparable to, but different from, the phenomenon of speech: as another way of speaking, a field of symbolic production created by human beings (Cardona, 1994).

Some authors consider that with writing a new mental space was born, a new ecosystem for thought, which marks the subject in such a way that it is impossible to return to an oral past (Illich, 1991); they consider writing as a "superior tool" compared with speech, because it makes expression more public, more accessible to more people and it makes meaning more constructible. Aside from these exaggerations, writing would represent a second milestone, following the word, in the cultural evolution of humanity (Havelock, 1963). Perhaps the most influential exaltation of reading and writing was that made by M. McLuhan (1962) who affirms that from the integration of a sound without meaning and a graphic sign without meaning the very form and sense of Western man was constructed. In this sense, Olson (1994) calls written production "literary artefacts" and invites us to study its properties as such and not only those of the symbolic content of what we find "written" in them. These forms add the perennialization of messages to word and memory, not because of their association with the word, but because of the association between the message and it physical medium. Writing is the final result of applying the graphic function to symbolic communication, the visual registry of thought, which the power of images today takes to new heights. These "minor" matters of the materiality of the invention, or those of the invention of the code and system of signs, whether alphabet or ideogram, were what made possible all the other effects and their socialization (Audin, 1972), which in turn caused changes to occur in ways of life that were not the consequence of assimilating the meaning of a text, but of participating in the cultural context created by such artefacts.

The general principal dominating graphic systems from the beginning is that the relation between orality and the graphic system is not linear; both have their own autonomy and perform self-sufficient functions. Ideographic functions and logographic functions can thus be differentiated right from the very birth of writing. Their differentiation allows us to understand the less verbal aspects of writing and situates us in the proper perspective for understanding the role of the book and the printing press. Besides alphabetic writing, we use other graphic systems such as the personal identity of the signature, trademarks, 
route and map signs, images used on labels and instruction leaflets for appliances and machines, traffic signs...

These considerations lead us to consider writing as a new mnemonic register and as a renewed instigator of epistemic functions: i.e., it touches the very structure of the activity of knowledge and this is why it is understood to be a decisive factor in the appearance and development of science. There is the generalized belief among researchers that "a written system is a visual function, at the same time that it is a set of cognitive skills” (Bennett \& Berry, 1998).

Goody (1986) points out that in at least three general areas of cognitive processes there is substantial although not systematic proof of effects derived from writing: the extraction and organization of information, the formation of plans of conduct and the elaboration of general theories. Goody concludes that both from a cognitive and a sociological point of view, writing has been "civilization", the culture of cities. The complex resources of the reading and writing system and the skills developed for its use provide new operational qualities for higher mental functions. However, it cannot be affirmed that all this implies a change in the structure of the mind. Some authors went beyond this limit. In the first quarter of the last century Lévy-Bruhl (1922) suggested that the differences between oral cultures and reading-writing cultures corresponded to differences in mental functioning.

In reading and writing societies almost all social activity is wholly or partially mediated by this technique, from services to mobility in space. The process of elaboration of the graphic function progresses parallel to all the social-cultural values associated with it: aesthetic function, the profession of scribe, refining of transactions, refining of the interpretation of the registered meaning. The uses of writing were basically applied in two directions: social management and knowledge activity. It opens two roads to progress: in social organization and in knowledge of the world.

Olson (1994) considers that writing with syntax comprised the first suitable model for speech, as well as the possibility of representing abstract amounts. It therefore makes possible the awareness of the structure of speech and the structural analysis of language. With it, words acquire the condition of objects for reflection. Today these statements 
lead to the idea that children acquire the notions of syllable, word, sentence, verb... by learning writing. The invention of writing is concomitant with the discovery that what is said has properties. The artifice of writing also made possible the elaboration of other literary artefacts such as logics, grammars and dictionaries.

The condition of actor and author in reading and writing societies became transformed; to be one and/or the other, competence in reading and writing was a necessary condition; a lack of such competence gradually became a cause for marginalization. Marginalization became more and more obvious as the literate began to associate their social dynamics to written communication more intensely and indissolubly. Those who possess these skills are potentially actors and/or authors. The latter condition requires several mental abilities:

- Discursive abilities through which thought can be organized linearly on a theme until the whole course is run; given the possibilities that the new system of memory-content retrieval presents, the content of the artifices and limitations of oral discourse and subjective memory can be released.

- Narrative abilities through which the reader's comprehension, the following reflection, anticipation of difficulties and questions and expressive simulation of situations are facilitated.

- Parallel to the author's abilities, composition strategies and reproduction techniques were developed as interfaces for duplicating information.

\subsection{Hypertext as an Educational Resource}

Traditionally, instructors have used linear models in order to transmit the knowledge. Spiro's Cognitive Flexibility Theory (Spiro, 1987; Spiro et al., 1988) suggests that is not a problem when information being presented is well-structured and simple, i.e., when an introductory view is given; but this linear models fail when the students have to create a deeper knowledge space, because they need a complex and ill-structured architecture of data. In this way, hypertext provides a nonlinear, multi-dimensional medium in which represent complex subject matter that traditional systems, such as books or lectures, lack (Spiro \& Jehng, 1990; Spiro et al., 1992).

Theodor H. Nelson (1965) defines hypertext as “a body of written or pictorial material interconnected in such a complex way that it could not conveniently be presented or 
represented on paper”. Rapidly, the hypertext systems evolved to hypermedia systems, where hypermedia could be defined as the style of building systems for information representation and management around the network of multimedia nodes connected together by typed links (Halasz, 1988; Halasz, 1991).

In the context of this work we are going to consider hypermedia our world of study, because it represents the possibility to integrate graphics, text, sound, animation and video in one educational resource, with the addition of the capability to freely navigate between and within concepts, being a broader term that the multimedia concept.

In this section, we are going to introduce the hypertextual base that is presented in the virtual systems (especially in educational ones), the necessity of specialized tools to create quality hypertext text and the difficulties that non-technical authors find in this new ICT (Information and Communication Technologies) based world.

\subsubsection{Informatics as a Communication System}

Human beings, as we have seen, have always lived in information societies and within structures of task-distribution where information was one of the "raw materials". Training in behaviour was always associated with the understanding of the design of the action or the understanding of the design of textual artefacts. "Works and works in preparation (drafts) create in a group shared and negotiable ways of thinking” (Bruner, 1996). The "impact" or implantation of a new system of communication, a new "skin of culture” (Kerckhove, 1995), has taken place on top of this primordial evidence, with such surprising effects that we fall into the metonymy of describing the event as "the entry of the Information Society". The basic communicational innovation consists in the fact that, now, it is information that is moving and becoming accessible without even the limits imposed by the rigid medium of the written text.

After the radio, telephone, television and digitalized communication, we have finally admitted a "revolution in communications": because of their consequences for intersubjectivity, for co-existence, and because of the consequences for the symbolic system for thought. In the opinion of Javier Echeverría (1999), this revolution is associated with the development of various technologies, among which are: the telephone, radio, television, telematic networks, electronic money, multimedia and 
hypertext.

The consequences for the structure of social interaction are referred to by spatial metaphors: global village (McLuhan \& Fiore, 1968), global city (Brzezinski, 1970), telepolis (Echeverría, 1994), technopolis (Postman, 1993), cybersociety - cyberspace (Joyanes, 1997), digital society (digital existence) (Negroponte, 1995), global empire marketplace (Bakos, 1998, Segev et al., 1999), virtual world (Echeverría, 2000). The consequences for the symbolic system are known as globalization (Beck, 1997; Beck 2000).

The scale of analysis that ranges from structural information on way of life (syntactic information or consequences deriving from the very structure of the technology) to semantic and pragmatic information should be applied to this new state of communications. We should not forget that in McLuhan's thought there were two perspectives, that of the "Global Village" and that of "the medium is the message". Negroponte (1995) stated it very clearly, "the transformation of atoms into bytes is irrevocable and unstoppable”.

We think that it is important to deconstruct this form of discourse and situate the cultural event inside its proper limits and its proper equivocations: it is a question of the introduction of a new digitalized information technology and the appearance of a new “communication system”, a new environment of communicative action, but we are still flesh and blood. The basic problem is still the same: we have a system of artefacts that allows new complexities of action, but what should the content of this action be? Versus the importance given to possessing and acquiring technology, we must stress the importance of creating contents, promoting criteria of access to the contents, guiding and orienting access to the communicational and informational sources available with the technology (new ways of educational orientation), and favouring new forms of critical thought, since some of the ways in which the new medium presents content have an ambiguous and equivocal relationship to the reflection and thought they seek to foster.

If the effects of linguistic artifices on thought and the effects of literary artefacts on the activity of knowledge were true, those who aspire to playing the main role in actions of 
education and communication must, in collusion with the new system of communication, force themselves to think in hypermedia frameworks. Educational planning in the cultural world of the book was founded on the systematic concepts of proposition systems (highly characteristic of the written form of communication); the informational context also facilitates the treatment of situations.

Until now the most accessible and generalised applications are those that break with the unit of space, creating possibilities for action at a distance (e.g. virtual university, chats...), and break with the unit of time, because of the unlimited capacity for storing information. Except for the illusion, however, the frontier between the screen and the spectator does not dissolve.

The term virtual has been extended to all possibilities of action created since computers have been in use: virtuality of communication (agduj5@usal.es), of jobs and production relations (virtual tutor), of place (http://www.usal.es), of going to the institution (virtual campuses...), tele-work, virtual class (Tiffin \& Rajasinghan, 1995). But a virtual environment strictly speaking is "an interactive, graphic database, that can be explored and visualized in real time in the form of three dimensional images of synthesis able to cause a sensation of being immersed in the image" (Quéau, 1993). In order to have the experience of movement, visualization devices are used (stereoscopic helmet, goggles, stereophonic headphones, digital gloves, movement sensors...). In general, they remain within the sphere of audiovisual perception and include person-machine interactivity, the limitation of which depends on each case. If we accumulate the possibilities of action generated since digitalisation began, we face a real environment of activity in expansion; the term virtual merely refers to the fact that the medium of activity is digitalisation and the technology of its applications.

\subsubsection{The author of educational resources in the Information Society}

The generation gap created by the introduction of a new system of communication does not respect economic condition, social status or level of knowledge. Once again, recovering the position of author in the communicational context created by ICT reproduces situations of marginalization analogous to those of the reading and writing context. For the time being these are less apparent because the spread of ICT is still only partial; in many fields it does not yet affect professional competence (it maintains the 
role of orality and of reading and writing); the necessary information is still reproduced in several media (written and informational); social demand is still rather undefined (it is still satisfied merely with the book).

However, in many fields of knowledge the hypermedia text has notable informative advantages over the written text (e.g. in medicine, art history, biology...). We shall not dwell on this matter since it is evident.

A basic problem lies in the fact that, given the technological nature of computer resources, the position of hypermedia author, besides requiring the skills described in the previous paragraph, also requires sophisticated technological skills, specifically competence in the so-called "authoring tools".

We believe that, just as use of the computer has become democratized through computer-user interfaces, it is necessary to democratize the function of author of hypermedia educational resources. There is an urgent need for the development of interfaces between author software and real authors in order to bridge the gap between the educators and technical issues. In this sense the authoring tool never should lose sight of educational goals, and thereby the hypermedia resources should frame the student's interaction within pedagogic context.

\subsubsection{Technical difficulties for the potential authors of hypermedia contents}

The creation of hypermedia documents differs considerably from the creation of contents in the traditional way, mainly because in hypermedia documents the author partially loses the authority to determine how a work should be followed, given that hypermedia systems are a priori more flexible, and the readers are free to explore the information as they wish. Consequently, the authors of hypermedia contents must offer other opportunities to their readers apart from strict sequential order.

Furthermore, the creation of a hyperdocument usually entails the use of other media such as sound or animation, among others, which on the one hand enrich the final system, but on the other hand may introduce new kinds of problems in structure and design when integrating them to the rest of the information elements. 
The main problem a potential author of hypermedia contents encounters is that of defining completely new text structures. Whereas printing is a stable industry, informatics is in a continual process of development. The text on paper conforms to a set of known rules that give rise to a series of expectations and skills. However, computer systems, such as hypertexts, do not usually follow conventions owing to the variety of domains, tasks and users to which they are addressed. All this means that many educators have still not become accustomed to structuring information in the hypertext way with the same ease with which they learned to write texts in sequence at school.

The process of constructing a hypermedia system is complex, and it entails the preparation of multi-medial material that will form part of the hyperdocument, the organization of the information, the integration of the elements of information into the final document and the definition of auxiliary structures, such as maps and indexes, in order to make it easier to consult and use the hyperdocument.

Also, the traditional view of hypertext has been swept by the wave of change of the WWW (World-Wide-Web). Now, on the Web, the hypertext base is combined with the functional properties that enhance the interaction and the complexity of these systems, which are so-called Web-applications.

There are several methodological proposals that aim at systematizing the creation of hypermedia (or Web) applications, such as HDM (Hypermedia Design Model) (Garzotto et al., 1993), HDM2 (Garzotto et al., 1996), RMM (Relationship Management Methodology) (Isakowitz et al., 1995; Balasubramanian et al., 2001), EORN (Lange, 1994), OOHDM (Object-Oriented Hypermedia Design Model) (Schwabe \& Rossi, 1995; Schwabe et al., 1996) or OOWS (Object-Oriented Web-Solutions) (Pastor et al., 2001) among others.

The hypermedia systems have evolved from monolithic ones to open hypermedia systems (Anderson et al., 2000). In the first generation hypermedia systems the primary requirements were to author, store, manage, and deliver unstructured information, but these new open systems are very complex systems that look directly at the Web, needing necessary a methodological support as the above-mentioned hypermedia design 
methodologies.

However, all these proposals exceed the interest and knowledge of the sector we are referring to in this article. This sector is formed by creators of educational contents who largely find themselves so left behind by the advances being made in computers that they would be completely overwhelmed by any methodological proposal so clearly affected by the life-cycle of software development, which, besides the phases proper to this kind of life-cycle, incorporate both structural and dynamic modelling techniques.

This situation emphasizes two main interest lines in the hypertext domain, those that see the hypertexts as a new form of literary expression and those that see these systems as a new form of application in the Web context. The former are so called literati, and the other ones engineers (Halasz, 2001). The literati are our objective collective, because they play the content-author role, independently if they are creating a closed hypermedia system or contents that will be integrated in an open and large Web system. In both cases the literati need suitable authoring tools, which are environments that facilitate the creation of hypermedia documents (Mendes \& Hall, 1999), i.e. they serve as an element of writing and editing for authors, providing them with a different type of authorship mechanisms.

From the early times, the hypertext authors had authoring environments, as HES (Hypertext Editing System) (Carmody et al., 1969), FRESS (File Retrieval and Editing System) (van Dam, 1971; DeRose \& van Dam, 1999) or IRIS Intermedia (Yankelovich et al., 1988; Haan et al., 1992), developed in 1960s, 1970s and 1980s respectively. Now, there are several commercial solutions for hypermedia authoring, for example MS FrontPage (http://www.microsoft.com/frontpage), Macromedia DreamWeaver (http://www.macromedia.com/software/dreamweaver/) or Storyspace (http://www.eastgate.com).

Once again we encounter the same drawback as in the methodologies; they are power tools with diverse features, but they are not designed for a user who is not an expert in computer skills and who is overwhelmed by the multiple options that these tools offer and, above all, by a person-tool interaction which has nothing whatsoever to do with the traditional way in which authors have created their educational contents for years. 
As a proposal we present an authoring tool called HyCo (Hypertext Composer) (García et al., 2003), which attempts to provide this group with an environment for the creation of hypermedia contents focused on the process of writing texts, and where the persontool interaction is based on the natural process that they would follow to create notes or a book. Besides, we have decided to develop a new authoring tool instead of using a commercial solution because we want to extend the HyCo environment in order to introduce in it new research dimensions in the hypermedia educational area such as semantic learning objects definition, collaborative work, adaptive capabilities and so on.

This tool is presented in the following section.

\section{The Facilitator for the composition of hypertexts}

HyCo v2 is an authoring tool that has been developed in the Laboratory of Multimedia Educational Design and Tele-Education of the Institute of Educational Sciences of the University of Salamanca by a mixed group of researchers comprising experts in Education and Computer Science.

The main objective of this tool, as has been stated throughout this article, is none other than to present a simple, friendly interface that makes the authoring process principles as transparent as possible to the user (Shneiderman, 1998), so that a teacher, not necessarily expert in computer skills, can become a creator of educational resources or hypermedia electronic books, which can be read by students via the WWW or off a CDROM.

The user-friendly capabilities of this authoring tool do not mean that this tool will be a simple hypertext editor. This way, HyCo has an important semantic basis behind its human-computer interaction process that nears this tool to the Semantic Web concept (Berners-Lee et al., 2001) and allows creating semantic learning objects that could be imported for more specialized Learning Management Systems (LMS), or defining adaptive hypermedia documents.

HyCo is at the same time an authoring tool and a reader tool, in that it encapsulates all the complexity in handling current tools within the facilities that the author needs, and 
offers as a result a hypermedia teaching product, which can be distributed in different formats for the user access.

\subsection{The authoring process}

When an author is going to create a text, whether educational or not, it is advisable, not to say essential, to organize the contents, in order to improve the clarity and quality of the final result. A commonly accepted way of carrying out this organization is to make a prior index of contents, without a theoretical limit of nesting levels (but with a practical limit for the sake of clarity), so that we obtain a hierarchical structure that guides us in our creative process, which would consist in associating contents with each index entry, an index that may vary as the contents take shape, by inserting, eliminating or changing entries. Each index entry gives rise to a thematic unit or lexia that can contain text, multimedia material and links with other units or documents.

In a nutshell, then, HyCo authoring tool faithfully reproduces the process previously explained in which an author could create a linear educational resource, but it channels it, at the same time as it organizes it, through the metaphor of the content index, adding the facilities for including multimedia elements (images, videos, sound...).

This indexed or tree structure facilitates the authoring of the hypertext, but having only an index as navigation tool is not acceptable in order to create real pedagogical hypermedia resources where the student may construct its own knowledge. This way, the hyperdocuments should be designed in such a way as to encourage the readers to see the same text in as many useful contexts as possible. This means placing texts within the contexts of other texts, including different views of the same text (Jones \& Spiro, 1992).

For the above-mentioned reason HyCo also allows associating links to the multimedia elements that compose an index entry, i.e. a hypertext node. This way, the hypertext can be followed by its index-structure, but when a node is selected, the reader may choose navigating by an existing link. Thus, HyCo documents combine both content index and Web-like structures.

The content index metaphor is directly supported in the user interface, which is frame 
structured. The left part of the screen shows links to every part of the hypertext structure and the main frame is the writing/displaying area. The Web metaphor is supported by two buttons that allow creating or modifying the links. The main interface is completed with a toolbox area, which allows inserting, erasing, or renaming the entries of the structure, and with an information area, at the lower right corner, where the characteristics of the selected link (type of link, name, description...) are displayed, as it is shown in Figure 1.

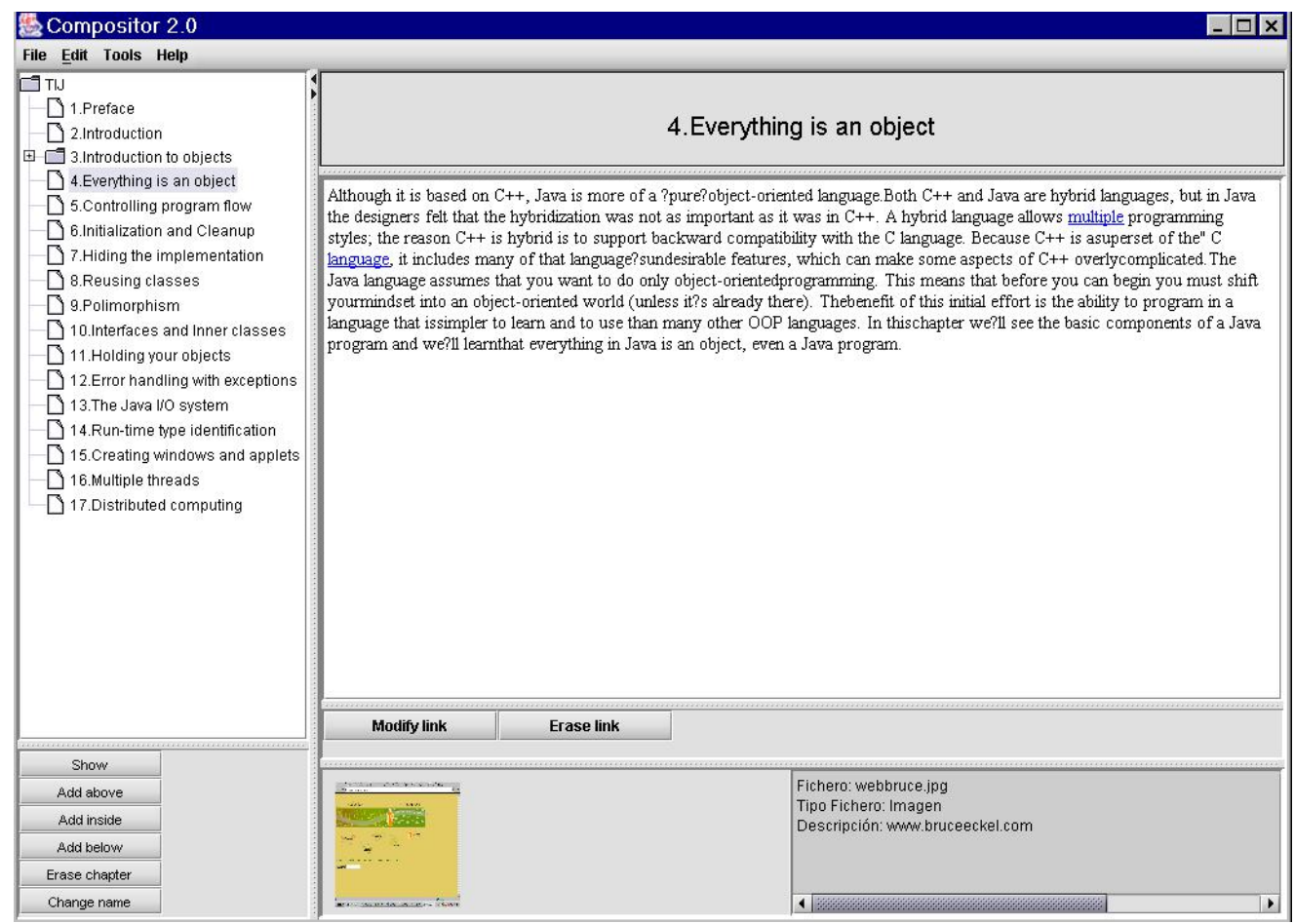

Figure 1. HyCo authoring interface

This organization, besides creating a work metaphor easily assimilated by anybody who has previously written any type of hierarchical document, allows direct translation to a well-organised hyperdocument and all that has to be taken into account is that each lexia corresponds to a node of the hyperdocument.

The lexia-node equivalence is the basis for the success of the creation process because the node, the same as the lexia for the author, is a unit of information in which a series of contents of diverse nature are combined to transmit an idea or concept. The node is a unit of visualization that will facilitate the work of the navigators to show the hyperdocument and navigate through it. 
The index of the document serves as a navigator to move to the different lexias that comprise the hyperdocument, so that in author mode it makes it possible to gain access to the lexia in which one wishes to work, or else, using a contextual menu, make the changes to the index that the author considers necessary whereas in the reader mode, together with the hyperlinks, it represents the way to navigate through the hyperdocument.

\subsection{The galleries}

A hyperdocument complements the text with information of a varied nature. One problem for the author is how to keep this information organized with a view to its possible publication in a medium other than the authoring tool itself.

In this sense HyCo v2 keeps a repository of information linked to each document created with a tool, so that the location of this type of resource is largely solved. But moreover, so that it can be managed by the author, a series of interfaces based on the metaphors of viewer and form are incorporated and receive the name of galleries.

A gallery is a manager of all the information, classified by types, which the user can associate to a hyperdocument. In the author mode, the gallery is a shared repository of elements for the hypertext creation, i.e. the elements included in the gallery can be independently managed of the authoring process. In the reader mode, the gallery presents only the elements that belong to the hypertext.

The gallery metaphor was initially thought to manage the multimedia elements, but the success of this metaphor for the users of the HyCo has prompted the extension of this concept in order to manage other properties of the document, specifically the styles and the output formats.

The first kind of gallery is the multimedia gallery. There are three different multimedia galleries, the Image Gallery, the Video Gallery and the Sound Gallery. Each one allows inserting, modifying or deleting multimedia elements (images, videos and sounds respectively) and the later linkage in the document of them. 
The multimedia galleries present the multimedia elements organized in sets of six components. It is possible the pre-visualization of the element, searching elements and so on. Figure 2 shows the Image Gallery (in this case a capture showing an interface in Spanish has been chosen in order to show the internationalization capabilities of the HyCo).

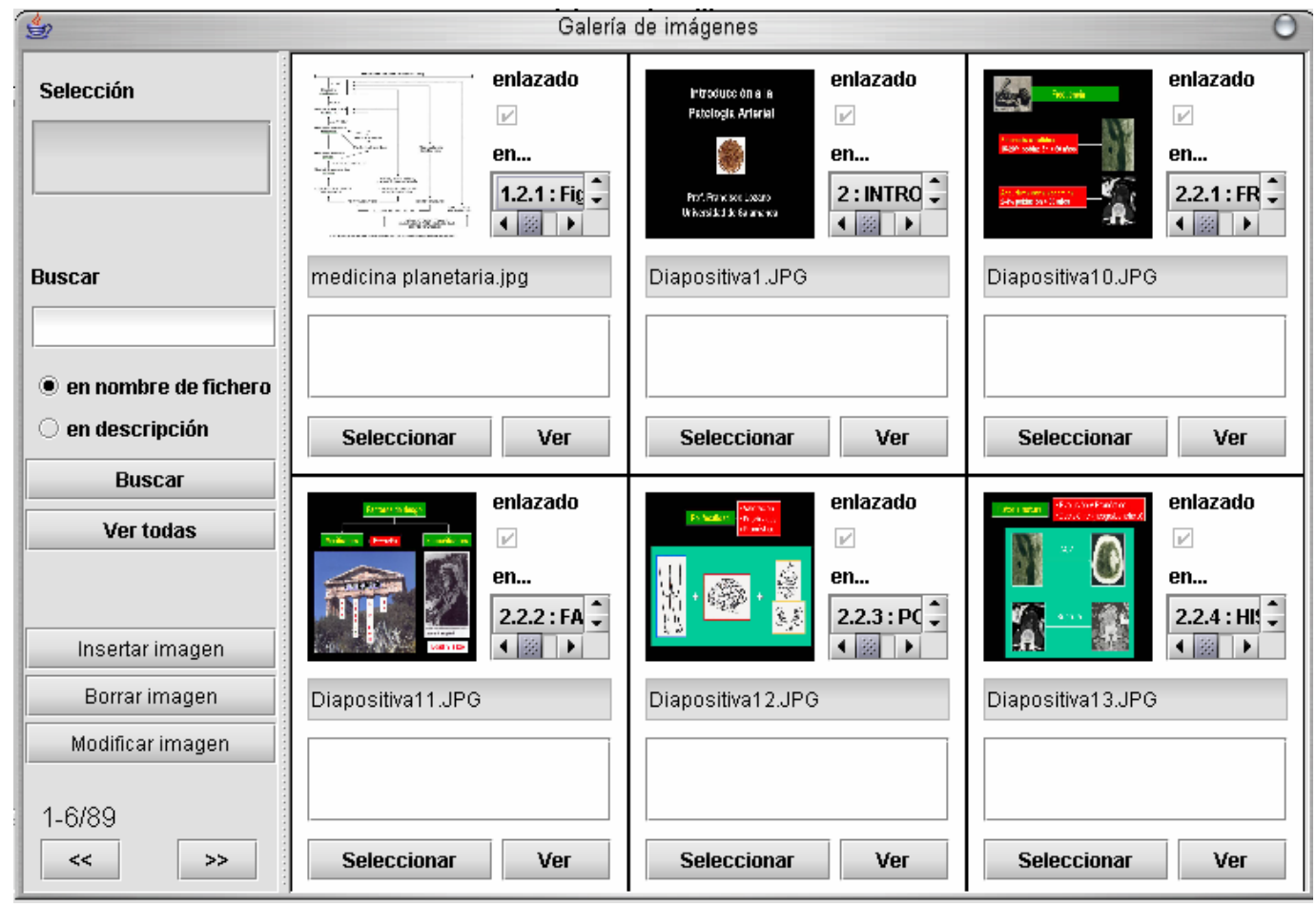

Figure 2. Image Gallery

Other important gallery is the Bibliography Gallery. This one allows an advanced treatment of the bibliographic references. It is composed of other minor galleries that manage the authors, classification areas and disciplines. HyCo v2 has a bibliographic references management based on the treatment done in LaTeX systems (Lamport, 1986), i.e. the user insert a reference key in the text body, and later in reader mode the keys are substituted by the right reference and a Reference Section is automatically generated at the end of the hypertext.

In order to facilitate the management of the bibliographic references the Bibliography Gallery presents a four-step wizard that allows defining completely a reference (see Figure 3). Steps two and three use drag and drop to make easier the attachment of the authors, areas and classification data of the reference. Nine kinds of references are 
supported: article, proceeding, electronic document, technical report, in proceedings paper, book chapter, book, thesis and others.

Two auxiliary galleries close the set of supported galleries. The first one is the Style Gallery, which is devoted to change the style and the size of the font used in the editor. The other is the Output Gallery that allows to the user choose a format to export the document if we want to use the created resource with external tools. The basic supported output formats are HTML, RTF, PDF, PostScript, SVG and plain text, as it is shown in Figure 4. Also, the Output Gallery allows selecting the elements, the font type and size, and the bibliographic style (APA, ACM or Default) that should appear in the final format.

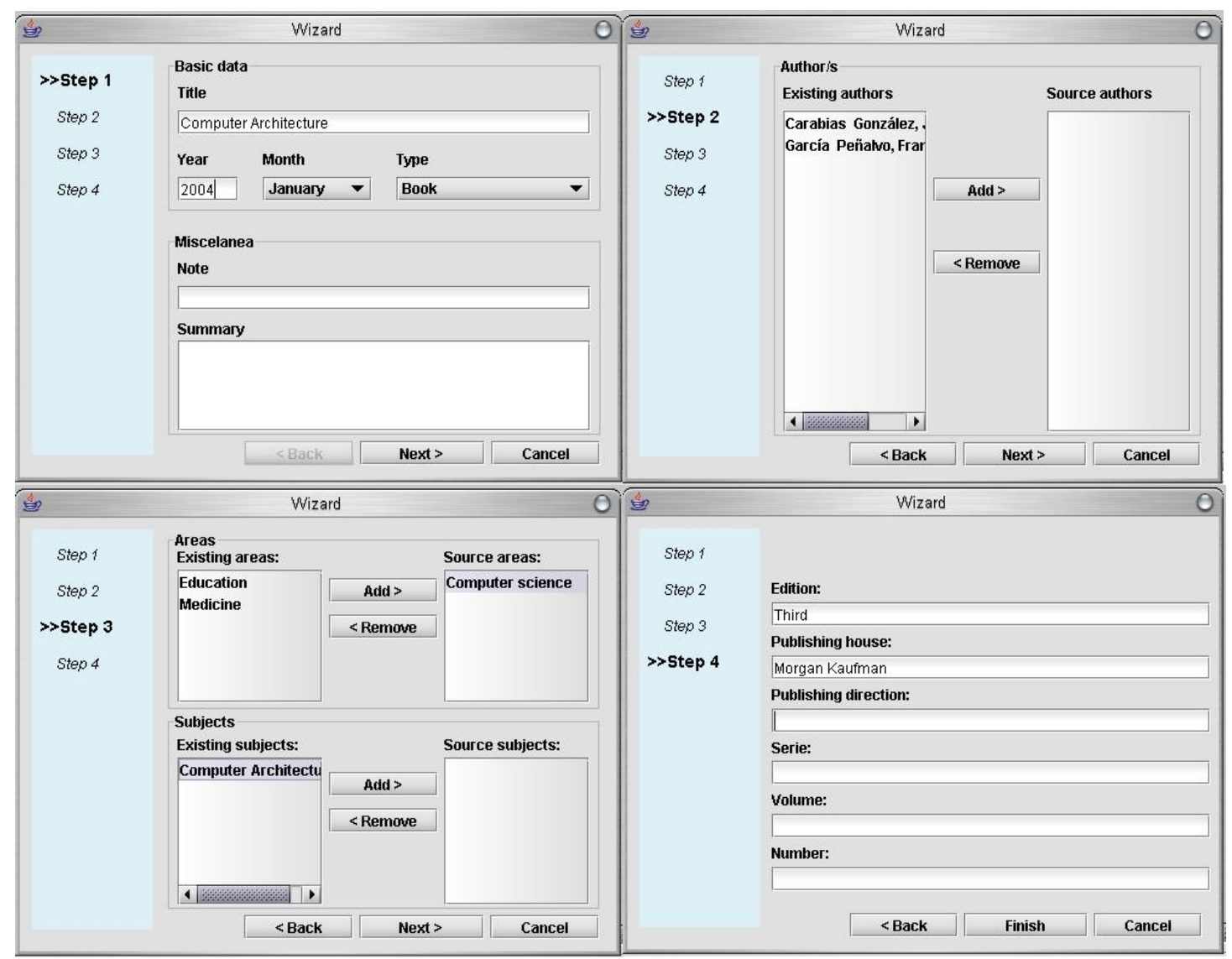

Figure 3. Bibliographic reference wizard 


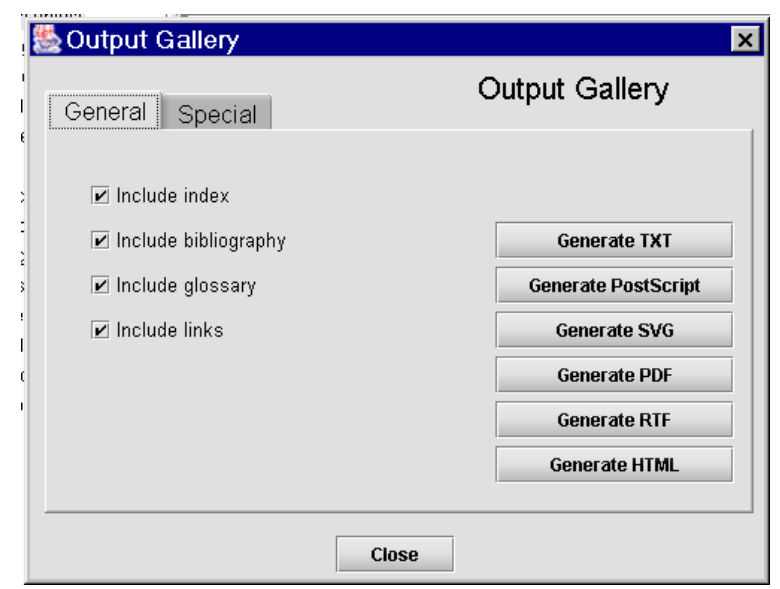

Figure 4. Output Gallery

\subsection{Semantic storage of the HyCo resources}

From the first version of HyCo, we have claimed for a separation between the educational contents and their formats. First, we used XML (eXtensible Markup Language) (Bray et al., 2004) as internal storage format, because of its great penetration in recent times and because of its incredible capacity to adapt to different platforms, thus making it possible to export to other formats.

However, in HyCo v2 we have gone one step beyond. We want to produce better learning elements with our authoring tool: they should be reusable, interoperable, durable and accessible. To accomplish these requirements, several Learning Technologies Standards (LTS) have been developed in the international community and their utilization in the instructional design should be considered and evaluated by learning technology developers.

LTS are agreements about the characteristics a learning element should have in order to be compatible, interchangeable and interoperable into other learning systems. The use of standards ensures instructional technologies interoperability, and their learning objects, for universities and corporations around the globe (Wiley, 2000).

In a first approach we decided to include among these capabilities the possibility to generate for each hypertext an output file tagged according with the EML specification (Educational Modelling Language) (Koper, 2001), and vice versa, the option to upload an EML input file that can be seen as a HyCo resource. To download the EML file it is 
necessary to indicate learning objectives, prerequisites and roles that will be included.

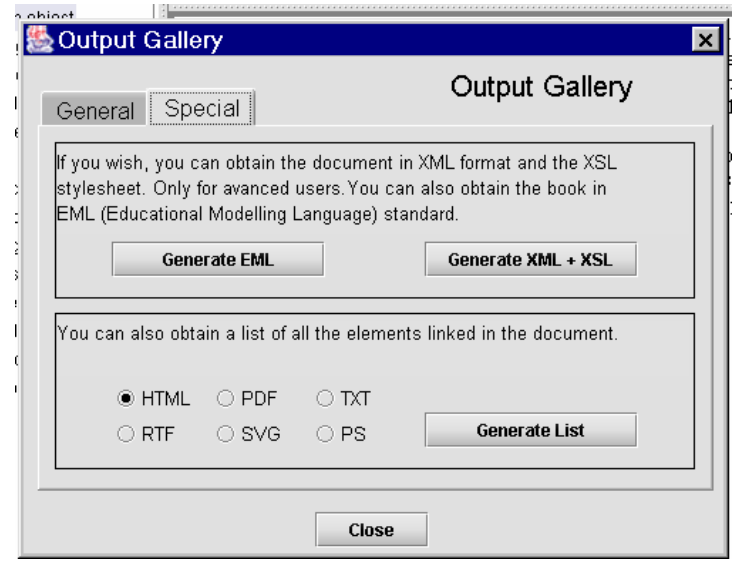

Figure 5. Semantic options in the Output Gallery

In order to export a hypertext as a semantic resource, the Output Gallery has been extended with a "special" tag, as it is shown in Figure 5, in which the document can be exported as an XML file with a style sheet XSL file or in EML format.

\subsection{Voice synthesis in the reader mode}

Another interesting feature of the HyCo v2 is the introduction of voice synthesis capabilities in reader mode.

The voice synthesis is a text to sound transformation process, which allows creating an artificial voice. This way, in the reader mode the user can listen to the contents. This feature offers accessibility possibilities to handicapped people, as blind people for example, in order to access to the educational contents.

\section{Related works}

There are many different hypermedia authoring tools that could be used in order to produce hypermedia system for education domain. Some of them are commercial ones, whereas many others have been developed for educational and research goals. Our proposal, HyCo v2, has not commercial ambitions by now, and we decided developing our own solution in order to achieve our research goals in which appear semantic, adaptive and collaborative issues, some of them are presented in the actual version, others are in working prototypes and others will appear in future versions. Thus, in this comparison of HyCo authoring tool with other ones, the commercial feature is not taking in care. Instead of, and due to the enormous existing diversity, we have chosen 
five dimensions in order to make the comparison: open hypermedia compliant systems, design metaphors used to create the systems, semantic characteristics, collaborative characteristics, and adaptive and intelligence characteristics.

\subsection{Open hypermedia compliant systems}

Hypermedia systems have evolved from closed hypermedia systems to open hypermedia systems (Anderson et al., 2000).

Closed hypermedia systems store both content and hypermedia structures internally (monolithic systems) or in a database. External application or information cannot easily participate or be included in the hypertext system. These systems produce self-contained hypermedia systems, but they do not support heterogeneity, particularly they do not support hypertext distributed over multiple heterogeneous managers. Examples of these systems are Apple HyperCard (Goodman, 1987), KMS (Akscyn et al., 1988), IRIS Intermedia (Yankelovich et al., 1988; Haan et al., 1992), SEPIA (Structured Elicitation and Processing of Ideas for Authoring) (Haake \& Wilson, 1992; Streitz et al., 1992) or Storyspace (Bernstein, 1991).

There are two complementary means of open hypermedia; the first one is the ability to integrate distributed information (Henze \& Nejdl, 2001), whereas the other one is the property to store their content outside the hyperbase, especially keeping linking information separate from documents and allowing for more powerful link structures, for example bi-directional or n-ary links (Reich et al., 1999; Millard et al., 2000). Some examples of these open hypermedia systems are KBS (Henze, 2000; Henze \& Nejdl, 2001), Chimera (Anderson et al., 2000), HyperDisco (Wiil \& Leggett, 1997a) Hyperform (Wiil \& Leggett, 1997b) or DHM (Grønbæk \& Trigg, 1994).

HyCo inherits properties from both closed and open hypermedia systems. HyCo presents a reader mode, in which the hypertext can be navigated within the tool, in a self-contained way like in the classic authoring systems as Intermedia or Storyspace. In addition, HyCo has voice synthesis capabilities in order to make more accessible the developed hypertext system. The differentiation of the author and reader roles in the same authoring tool differs from other systems that only present authoring capabilities as MS FrontPage (http://www.microsoft.com/frontpage). 
About the use of external versus internals links, HyCo v2 follows a comprise between these approaches by storing links internally but representing them externally. Links are stored inside the educational resource, this way users have not separate link files that could cause wrong opening operations. But HyCo links are represented separately and compactly, rather than being spread implicitly through the system. This idea is based on the link system of Storyspace v2 (Bernstein, 2002) and Chimera, instead of the embedded link model of the HTML (Raggett et al., 1999), which is one of the most notably weaknesses of the WWW (Berners-Lee, 1996). Other common option is to use a database to store the hypermedia structures and the contents as it occurs for example in SEPIA or IRIS Intermedia.

Also HyCo has an important set of interoperability and integration capabilities, which are represented in its exporting features that allow having the hypertext system integrated in the WWW through the HTML exporting capabilities, integrating the hypertext context with external applications through the RTF or PDF exporting capabilities, or interoperating with LMS that manage semantic learning objects by the EML support. Typical exporting capabilities can be found in other authoring tools, for example Intermedia supports ASCII and Microsoft Word exporting, and Storyspace exports to HTML, HyperCard or MacWrite.

\subsection{Design metaphors used to create the systems}

Hypermedia authoring tools can be categorized by the main design metaphor used to create the hypermedia system (Elliot et al., 2002).

HyCo presents a content index metaphor. Apple HyperCard (Goodman, 1987) or Asymetix ToolBook uses a book metaphor that is near to HyCo content index metaphor. IRIS Intermedia (Yankelovich et al., 1988; Haan et al., 1992) and Storyspace (Bernstein, 1991; Bernstein, 2002) use a map metaphor. MS FrontPage (http://www.microsoft.com/frontpage) is based on the directory and file metaphors. Macromedia Authorware presents a control flow metaphor. The card metaphor has been used in several systems, for example in NoteCards (Halasz, 1988).

In our experience the index content metaphor is more adequate for non experienced 
users because it reproduces better their usual creational process, whereas the map metaphor is more appropriate for advanced users, and control flow metaphor is more presented in multimedia oriented authoring tools.

\subsection{Semantic characteristics}

In order to guarantee interoperability and reusability of the content created by means of HyCo, this authoring environment bets on Semantic Learning Objects (SLO) based on LTS.

A similar proposal can be found in HYLOS (Hypermedia Learning Object System) (Feustel \& Schmidt, 2001; Engelhardt et al., 2002). This system is devoted to create ELearning Objects (ELOs) instead of HTML-pages. In this case they complete the contents with its metadata to compound an ELO. The used metadata are a subset of the LOM (Learning Object Metadata) (IEEE, 2003).

In HyCo v2, the EML (Koper, 2001) has been initially chosen as LTS, but due to this standard is being considered deprecated, we have changed the supporter format for SLOs to IMS specifications, specifically in order to describe SLOs it uses IMS Metadata (IMS, 2003).

\subsection{Collaborative characteristics}

Actually, HyCo v2 only presents a minimum collaborative behaviour in the reader mode, because a reader can access to a remote hypertext with only-read privileges, and this resource could be acceded for many users at time. This capability was yet presented in Storyspace (Bernstein, 1991; Bernstein, 2002) and also in Intermedia (Yankelovich et al., 1988; Haan et al., 1992), but in this last one multiple users can read and annotate a single document, and only one user can write to a document at time, the first user to edit the document content locks out all other users from editing the document until it is closed (Garret et al., 1986).

One further work in the HyCo system is to develop a collaborative/cooperative authoring process that allows an individual mode and different coupled modes as SEPIA does (Haake \& Wilson, 1992; Streitz et al., 1992), using the ability to access workspaces distributed across the Internet, which contain hypermedia information as 
well as content as for example occurs in HyperDisco (Wiil \& Leggett, 1997a), and taking into account the cooperative hypermedia framework proposed by Tata et al. (2002).

\subsection{Adaptive characteristics}

The most active research line related to our authoring tool is to take advantage of the characteristics of HyCo as authoring tool to create educative contents in an Adaptive Learning Environment (ALE) (Berlanga \& García, 2003; Berlanga et al., 2003).

The research in this line is starting, and we have no enough results in order to compare with other authoring tools for adaptive systems such as for example AHA! v2 (De Bra et al., 2002), Metalinks (Murray, 2003) or WEAR (Moundridou \& Virvou, 2001; Moundridou \& Virvou, 2003). For further reading about this kind of authoring tools we refer the reader to (Brusilovsky, 2003).

\section{Conclusions}

With the incorporation of hypermedia environments, the role of the teacher is changed from a mere transmitter of knowledge to that of an organizer of activities and learning, giving the student greater autonomy and responsibility in the quest for learning. Furthermore the student comes to play a more active role in the educational process propitiated by the new technologies, becoming more motivated to use the available sources of information as well as those recommended. These innovations bring about a change in the concept of classroom, seen as a physical entity, so that the notion of virtual classroom, a space that the student can use without restrictions of time and space, becomes more meaningful; this is becoming more of a reality with the incorporation of telematic facilities to education through the Internet, and the proliferation of Web portals devoted exclusively to education. All these contributions promise more effective learning which will have positive repercussions on the student's subsequent performance in today’s society.

However, although this situation cannot be denied or ignored, one of the major concerns of our work group is the barrier that information technologies impose on many teachers, who find themselves technologically ostracized and become shut out of current educational processes. Our intention is to recover them as authors of educational 
resources for tele-education by creating tools made to measure for them and not for computer experts, designed from a pedagogical point of view with facilitating and integrating interfaces.

To illustrate this situation we have outlined the communication processes of human beings from orality until the digital age of today, expressing the difficulties that the methodologies as well as the authoring tools for the creation of hyperdocuments pose to this sector.

Finally, our solution proposal to this problem is an authoring tool, HyCo, which is designed to facilitate the composition of hypertexts so that, by means of a simple and extremely intuitive interface, any teacher with a minimum knowledge of computers can transform his or her experience and knowledge into useful educational resources, and thus be recovered as an author if, as experience has frequently shown us, this teacher had been left out because of the technological filter.

The success of the HyCo authoring process, which basically based on the content index metaphor, has been proved because three educational hypertext systems have been created with this tool. Two of them are drafts devoted to test the authoring tool, one about computer history and other one about a software engineering course. But the third one is a complete electronic book in hypermedia format about cardiovascular surgery that is formed by 14 chapters, more than 500 sections and over 1000 images. This book is successfully used in the lectures of this subject in the University of Salamanca.

This tool does not seek to compete with any other in the market because, as has been made clear throughout this article, the existing tools are far too difficult for the group to which our authoring tool is addressed, and in an open environment they can co-exist to enrich the virtual educational spaces that little by little are finding a place in all levels of the educational process.

HyCo is an open system in which too much further work is going to be done, especially in collaborative and adaptive aspects. 


\section{Acknowledgements}

We would like to thank the AWEG - Adaptive Web Engineering Group - of the University of Salamanca for its ideas and support to the elaboration of this paper.

This study was partly financed by the Regional Government of Castile and Leon through research project SA017/02. Also, it is supported by the European Union Project ODISEAME (Open distance Interuniversity Synergies between Europe, Africa and Middle East), ref. EUMEDIS B7-4100/2000/2165-79 P546.

\section{References}

Akscyn, R. M., McCracken, D. L. \& Yoder, E. A. (1988). KMS: A Distributed Hypermedia System for Managing Knowledge in Organizations. Communications of the ACM, 31(7), 820-835.

Anderson, K. M., Taylor, R. N. \& Whitehead, J. (2000). Chimera: Hypermedia for Heterogeneous Software Development Environments. ACM Transactions on Information Systems, 18(3), 211-245.

Audin, M. (1972) Histoire de L’Imprimerie. Radioscopie d'une Ère: de Gutenberg à L’Informatique. Paris: Picard.

Austin, J. L. (1962). How to Do Things with Words. Oxford: Oxford University Press.

Bakos, Y. (1998). The Emerging Role of Electronic Marketplaces on the Internet. Communications of the ACM, 41(8), 35-42.

Balasubramanian, V., Bieber, M. \& Isakowitz, T. (2001). A Case Study in Systematic Hypermedia Design. Information Systems, 26, 295-320.

Beck, U. (1997). Was Ist Globalisierung. Frankfurt: Suhrkamp.

Beck, U. (2000). What is Globalization?. In D. Held \& A. McGrew (Eds.), The Global Transformations Reader: An Introduction to the Globalization Debate (pp. 99-103). Cambridge: Polity Press.

Belinchón, M., Igoa, J. M. \& Rivière, A. (1994). Psicología del Lenguaje. Investigación y Teoría. Trotta.

Bennett, J. A. \& Berry, J. (1991). Cree Literacy in the Syllabic Script. In D. R. Olson \& N. Torrance (Eds.), Literacy and Orality. Cambridge: Cambridge University Press. Berlanga, A. \& García, F. J. (2003). Espacios de Aprendizaje Adaptativos como Soporte Didáctico en los Procesos de Enseñanza y Aprendizaje. In M. Pérez Cota (Ed.), Actas del IV Congreso Interacción Persona-Ordenador - Interacción 2003. 
Berlanga, A., Morales, E. \& García, F. J. (2003). Learning Technology Standards: Semantic Objects for Adaptive Learning Environments. In A. Méndez, J. A. Mesa, J. Mesa (Eds.), Advances in Technology-Based Education: Toward a KnowledgeBased Society. Proceedings of the $2^{\text {nd }}$ International Conference on Multimedia and Information \& Communication Technologies in Education m-ICTE2003 (Vol. II, pp. 860-864). Consejería de Educación, Ciencia y Tecnología de la Junta de Extremadura.

Berners-Lee, T. (1996). WWW: Past, Present and Future. IEEE Computer, 29(10), 6977.

Berners-Lee, T., Hendler, J. \& Lassila, O. (2001). The Semantic Web. Scientific American.

Bernstein, M. (1991). Storyspace: Hypertext and the Process of Writing. In E. Berk \& J. Devlin (Eds.), Hypertext/Hypermedia Handbook (pp. 529-533). New York: McGraw-Hill.

Bernstein, M. (2002). Storyspace 1. In Proceedings of the Thirteenth ACM Conference on Hypertext and Hypermedia, HT'02 (pp. 172-181). New York, NY, USA: ACM Press.

Bray, T., Paoli, J., Sperberg-MacQueen, C. M., Maler, E. \& Yergeau, F. (Eds.). (2004). Extensible Markup Language (XML) 1.0 (Third Edition). World Wide Web Consortium Recommendation 04 February 2004. http://www.w3.org/TR/2004/RECxml-20040204.

Bruner, J. (1996). The Culture of Education (pp. 90-104). Cambridge: Harvard University Press.

Brusilovsky, P. (2003) Developing Adaptive Educational Hypermedia Systems: From Design Models to Authoring Tools. In T. Murray, S. Blessing \& S. Ainsworth (Eds.), Authoring Tools for Advanced Technology Learning Environment. Dordrecht: Kluwer Academic Publishers.

Brzezinski, Z. (1970). La Révolution Technologique. Paris: Calmann-Lévy.

Cardona, G. R. (1994). Antropología de la Escritura. Barcelona: Gedisa.

Carmody, S., Gross, W., Nelson, T. H., Rice, D., \& van Dam, A. (1969). A Hypertext Editing System for the /360. In M. Faiman \& J. Nievergelt (Eds.), Pertinent Concepts in Computer Graphics (pp. 291-330). University of Illinois.

Corredor, C. (1999). Filosofía del Lenguaje. Una Aproximación a las Teorías del Significado del Siglo XX. Madrid: Visor. 
De Bra, P., Aerts, A., Smits, D. \& Stash, N. (2002). AHA! Version 2.0: More Adaptation Flexibility for Authors. In M. Driscoll \& T. C. Reeves (Eds.), Proceedings of World Conference on E-Learning, E-Learn 2002 (pp. 240-246). AACE.

Denny, J. P. (1991). Rational Thought in Oral Culture and Literate Decontextualization. In D. R. Olson \& N. Torrance (Eds.), Literacy and Orality (pp. 66-89). Cambridge: Cambridge University Press.

DeRose, S. J. \& van Dam, A. (1999). Document Structure and Markup in the FRESS Hypertexy Systems. Markup Languages: Theory and Practice, 1(1), 7-32.

Echeverría, J. (1994). Telépolis. Barcelona: Destino.

Echeverría, J. (1999). Los Señores del Aire: Telépolis y el Tercer Entorno. Barcelona: Destino.

Echeverría, J. (2000). Un Mundo Virtual. Barcelona: Círculo Cuadrado.

Elliott, G. J., Jones, E. \& Barker, P. (2002). A Grounded Theory Approach to Modelling Learnability of Hypermedia Authoring Tools. Interacting with Computers, 14, 547574.

Engelhardt, M., Hildebrand, A., Kárpáti, A., Rack, T. \& Schmidt, T. C. (2002). Educational Content Management - A Cellular Approach. In Interactive Computer Aided Learning. Proceedings of the ICL2002. Kassel University Press.

Feustel, B. \& Schmidt, T. C. (2001). Media Objects in Time - A Multimedia Streaming System. Computer Networks, 37(6), 729-737.

Frisch von, K. (1967). The Dance Language and Orientation of Bees. Cambridge: Harvard University Press.

García, F. J., Carabias, J., García, J. \& Berlanga, A. (2003). HyCo - An Authoring Tool for Semantic Educational Resources. In A. Méndez, J. A. Mesa, J. Mesa (Eds.), Advances in Technology-Based Education: Toward a Knowledge-Based Society. Proceedings of the $2^{\text {nd }}$ International Conference on Multimedia and Information \& Communication Technologies in Education m-ICTE2003 (Vol. III, pp. 1670-1674). Consejería de Educación, Ciencia y Tecnología de la Junta de Extremadura.

Garrett, L. N., Smith, K. E. \& Meyrowitz (1986). Intermedia: Issues, Strategies, and Tactics in the Design of a Hypermedia Document System. In Proceedings of the 1986 ACM Conference on Computer-Supported Cooperative Work, CSCW’86 (pp. 163-174). New York, NY, USA: ACM Press.

Garzotto, F., Mainetti, L. \& Paolini, P. (1996). Navigation in Hypermedia Applications: 
Modeling and Semantics. Journal of Organizational Computing Electronic Commerce, 6(3), 211-237.

Garzotto, F., Paolini, P. \& Schwabe, D. (1993). HDM - A Model-Based Approach to Hypermedia Application Design. ACM Transactions on Information Systems, 11(1), $1-26$.

Goodman, D. (1987). The Complete HyperCard Handbook. New York: Bantam Books. Goody, J. (1986). The Logic of Writing and the Organisation of Society. Cambridge: Cambridge University Press.

Grønbæk, K. \& Trigg, R. (1994). Design Issues for a Dexter-Based Hypermedia System. Communications of the ACM, 37(2), 40-49.

Haake, J. M. \& Wilson, B. (1992). Supporting Collaborative Writing of Hyperdocuments in SEPIA. In Proceedings of the 1992 ACM Conference on Computer-Supported Cooperative Work, CSCW'92 (pp. 138-146). New York, NY, USA: ACM Press.

Haan, B. J., Kahn, P., Riley, V. A., Coombs, J. H. \& Meyrowitz, N. K. (1992). IRIS Hypermedia Services. Communications of the ACM, 35(1), 36-51.

Halasz, F. G. (1988). Reflections on NoteCards: Seven Issues for the Next Generation of Hypermedia Systems. Communications of the ACM, 31(7), 836-852.

Halasz, F. G. (1991). "Seven Issues”: Revisited. Keynote talk at the 1991 ACM Conference on Hypertext, HT’91. Available as Technical Report \#SSL-91-149. Xerox Palo Alto Research Center.

Halasz, F. G. (2001). Reflections on “Seven Issues”: Hypertext in Era of the Web. ACM Journal of Computer Documentation, 25(3), 109-114.

Havelock, E. (1963). Preface to Plato. Cambridge: Cambridge University Press.

Havelock, E. (1991). The Oral-Literature Equation: A Formula for the Modern Mind. In

D. R. Olson \& N. Torrance (Eds.), Literacy and Orality (11-27). Cambridge: Cambridge University Press.

Henze, N. (2000). Adaptive Hyperbooks: Adaptation for Project-based Learning Resources. PhD. University of Hannover.

Henze, N. \& Nejdl, W. (2001). Adaptation in Open Corpus Hypermedia. International Journal of Artificial Intelligence in Education, 12, 310-324.

IEEE. (2003). LOM Final Draft v6.4. http://ltsc.ieee.org/wg12/index.html.

Illich, I (1991). A Plea for Research on Lay Literacy. In D. R. Olson \& N. Torrance (Eds.), Literacy and Orality (28-46). Cambridge: Cambridge University Press. 
IMS. (2003). IMS Learning Resource Metadata Specification. http://www.imsglobal.org/metadata/index.cfm.

Isakowitz, T., Stohr, E. \& Balasubramanian, P. (1995). RMM: A Methodology for the Design of Structured Hypermedia Applications. Communications of the ACM, 38(8), 34-44.

Jones, R. A. \& Spiro, R. (1992). Imagined Conversations: The Relevance of Hypertext, Pragmatism, and Cognitive Flexibility Theory to the Interpretation of "Classic Texts” in Intellectual History. In D. Lucarella, J. Nanard, M. Nanard \& P. Paolini (Eds.), Proceedings of the $4^{\text {th }}$ ACM Conference on Hypertext - ECHT'92 (pp. 141148). New York, NY, USA: ACM Press.

Joyanes. L. (1997). Cibersociedad. Los Retos Sociales ante un Nuevo Mundo Digital. McGraw-Hill.

Kerckhove, D. (1995). The Skin of Culture Investigating: The New Electronic Reality. Somerville House Books.

Koper, R. (2001). Modelling Units of Study from a Pedagogical Perspective. The Pedagogical Meta-model behind EML. http://eml.ou.nl/introduction/docs/pedmetamodel.pdf.

Lamport, L. (1986). A Document Preparation System. Addison-Wesley.

Lange, D. B. (1994). An Object-Oriented Design Method for Hypermedia Information Systems. In Proceedings of the Twenty-Seventh Annual Hawaii International Conference on System Sciences (pp. 366-375).

Lévy, P. (1988) Qu’est-ce que le Virtuel. Paris: La Découverte.

Lévy-Bruhl, L. (1922). La Mentalité Primitive. Paris: PUF.

Luque, S. \& Alcoba, S. (1999). Comunicación Oral y Oralización. In S. Alcoba (Ed.) Oralización (pp. 15-45). Barcelona: Ariel Practicum.

Maturana, H. (1991). Science and Daily Life: The Ontology of Scientific Explanations. In F. Steier (Ed.), Research and Reflexivity. London: Sage.

McLuhan, M. (1962). The Gutenberg Galaxy. The Making of Typographic Man. London: Routledge \& Kean Paul.

McLuhan, M. \& Fiore, Q. (1968). War and Peace in the Global Village. New York: Bantam.

Mendes, M. E. X. \& Hall, W. (1999). Hyper-Authoring for Education: A Qualitative Evaluation. Computers \& Education, 32, 51-64.

Millard, D. E., Moreau, L., Davis, H. C. \& Reich, S. (2000). FOHM: A Fundamental 
Open Hypertext Model for Investigating Interoperability between Hypertext Domains. In F. M. Shipman III, P. J. Nürnberg \& D. L. Hicks (Eds.), Proceedings of the eleventh ACM on Hypertext and hypermedia, HT'00 (pp. 93-102). New York, NY, USA: ACM Press.

Moundridou, M. \& Virvou, M. (2001). Authoring and Delivering Adaptive Web-Based Textbooks using WEAR. In T.Okamoto, R. Hartley, Kinshuk \& J. P. Klus (Eds.), Proceedings of the IEEE International Conference on Advanced Learning Technologies; Issues, Achievements, and Challenges - ICALT'01 (pp. 185-188). Los Alamitos, California: IEEE-CS Press.

Moundridou, M. \& Virvou, M. (2003). Analysis and Design of a Web-based Authoring Tool Generating Intelligent Tutoring Systems. Computers \& Education, 40, 157181.

Murray, T. (2003). MetaLinks: Authoring and Affordances for Conceptual and Narrative Flow in Adaptive Hyperbooks. International Journal of Artificial Intelligence in Education, 13, In press.

Negroponte, N. (1995). Being Digital. Hodder \& Stoughton.

Nelson, T. H. (1965). A File Structure for the Complex, the Changing and the Indeterminate. In Association for Computing Machinery, Proceedings of the $20^{\text {th }}$ National Conference (pp. 84-100). New York, NY, USA: ACM Press.

Olson, D. R. (1994). The World on Paper. Cambridge: Cambridge University Press.

Parry, M. (1971). The Traditional Epithet in Homer. In A. Parry (Ed.), The Making of Homeric Verse. The Collected Papers of Milman Parry. Oxford: Oxford University Press.

Pastor, O., Abrahão, S. \& Fons, J. J. (2001). An Object-Oriented Approach to Automate Web Applications Development. In K. Bauknecht, S. K. Madria \& G. Pernul (Eds.), Electronic Commerce and Web Technologies, Second International Conference, EC-Web 2001, Proceedings (pp. 16-28). Lecture Notes in Computer Science. 2115. Berlin: Springer Verlag.

Postman, N. (1993). Technopoly: The Surrender of Culture to Technology. New York: Vintage.

Quéau, P. H. (1993). Le Virtuel: Vertus et Vertige. Seyssel: Champ Vallon/INA.

Raggett, D., Le Hors, A. \& Jacobs, I. (Eds.) (1999). HTML 4.01 Specification. W3C Recommendation. http://www.w3.org/TR/html401.

Reich, S., Wiil, U. K., Nürnberg, P. J., Davis, H. C., Grlønbk, K., Anderson, K. M., 
Millard, D. E. \& Haake, J. M. (1999). Addressing Interoperability in Open Hypermedia: The Design of the Open Hypermedia Protocol. The New Review of Hypermedia and Multimedia, 5, 207-248.

Saussure, F. de (1952). Curso de Lingüística General. Buenos Aires: Losada.

Schwabe, D. \& Rosssi, G. (1995). The Object-Oriented Hypermedia Design Model. Communications of the ACM, 38(8), 45-46.

Schwabe, D., Rossi, G. \& Barbosa, S. D. J. (1996). Systematic Hypermedia Application

Design with OOHDD. In Proceedings of the seventh ACM conference on Hypertext - Hypertext'96 (pp. 116-128). New York, NY, USA: ACM Press.

Searle, J. R. (1969). Speech Acts. Cambridge: Cambridge University Press.

Segev, A., Gebauer, J. \& Färber, F. (1999). Internet-based Electronic Markets. EM International Journal of Electronic Markets, 9(3).

Shneiderman, B. (1998). Designing the User Interface. Reading, MA: Addison-Wesley. Spiro, R. J. (1987). Knowledge Acquisition for Application: Cognitive Flexibility and Transfer in Complex Domains. In B. C. Britton \& S. Glynn (Eds.), Executive Control Processes in Reading (pp. 177-199). Hillsade, NJ: Lawrence Erlbaum Associates.

Spiro, R. J., Coulson, R. L., Feltovich, P. J. \& Anderson, D. (1988). Cognitive Flexibility Theory: Advanced Knowledge Acquisition in Ill-structured Domains. In V. Patel (Ed.), Proceedings of the $10^{\text {th }}$ Annual Conference of the Cognitive Science Society. Hillsade, NJ: Lawrence Erlbaum Associates.

Spiro, R. J., Feltovich, P. J., Jacobson, M. J. \& Coulson, R. L. (1992). Cognitive Flexibility, Constructivism, and Hypertext: Random Access Instruction for Advanced Knowledge Acquisition in Ill-structured Domains. In T. M. Duffy \& D. H. Janassen (Eds.), Constructivism and the Technology of Instruction: A Conversation (pp. 57-76). Hillsade, NJ: Lawrence Erlbaum Associates.

Spiro, R. J. \& Jehng, J. C. (1990). Cognitive Flexibility and Hypertext: Theory and Technology for the Nonlinear and Multidimensional Traversal of Complex Subject Matter. In D. Nix \& R. Spiro (Eds.), Cognition, Education, and Multimedia: Exploring Ideas in High Technology (pp. 163-205). Hillsade, NJ: Lawrence Erlbaum Associates.

Streitz, N., Haake, J., Hannemann, J., Lemke, A., Schuler, W., Schütt, H. \& Thüring, M. (1992). Imagined Conversations: The Relevance of Hypertext, Pragmatism, and Cognitive Flexibility Theory to the Interpretation of “Classic Texts” in Intellectual 
History. In D. Lucarella, J. Nanard, M. Nanard \& P. Paolini (Eds.), Proceedings of the $4^{\text {th }}$ ACM Conference on Hypertext - ECHT'92 (pp. 11-22). New York, NY, USA: ACM Press.

Tata, S., Godart, C. \& Wiil, U. K. (2002). Policies for Cooperative Hypermedia Systems. In Proceedings of the Thirteenth ACM Conference on Hypertext and Hypermedia, HT’02 (pp. 140-141). New York, NY, USA: ACM Press.

Tiffin, J., \& Rajasinghan, L. (1995). In Search of the Virtual Class: Education in an Information Society. London: Routledge.

van Dam, A. (1971). FRESS (File Retrieval and Editing System) User's Guide. Barrington: Text Systems, Inc.

Vigostky, L. S. (1978). Mind in Society. Cambridge: Harvard University Press.

Wiil, U. K. \& Leggett, J. J. (1997a). Workspaces: The HyperDisco Approach to Internet Distribution. In M. Bernstein, K. Østerbye \& L. Carr (Eds.), Proceedings of the eighth ACM conference on Hypertext, Hypertext 97 (pp. 13-23). New York, NY, USA: ACM Press.

Wiil, U. K. \& Leggett, J. J. (1997b). Hyperform: A Hypermedia System Development Envirnment. ACM Transactions on Information Systems, 15(1), 1-31.

Wiley, D. (2000). Connecting Learning Objects to Instructional Design Theory: A Definition, a Metaphor, and a Taxonomy. In D. Wiley (Ed.), The Instructional Use of Learning Objects. On line version: http://reusability.org/read/chapters/wiley.doc.

Yankelovich, N., Haan, B. J., Meyrowitz, N. K. \& Drucker, S. M. (1988). Intermedia: The Concept and the Construction of a Seamless Information Environment. IEEE Computer, 21(1), 81-96. 